\title{
The value of case reports in medical education
}

"Case reports are at the heart of medicine. They are how all doctors learn, and every patient, no matter how "ordinary" his or her problem has something to teach us" (Smith, 2009).

"Case reporting is arguably the oldest and most basic form of communication in medicine. The verbal presentation and explanation of a case history is a skill acquired early in undergraduate training and is a skill that most clinicians use throughout their careers"(Wildsmith, 2003). A similar skill is needed to generate a written case presentation, as both "positive" and "negative" features of the case have to be described in a logical sequence (Wildsmith, 2003). For many medical students and junior doctors writing a case report is their first experience of publishing (Carleton and Webb, 2012).

Case reports have been around for a long time. The Provincial Medical and Surgical Journal (now called the BMJ) was the first journal to publish case reports. Two articles appeared in the inaugural edition of 3rd October 1840 (Greenhow, 1840; No author, 1840).These cases were well described, to the extent that the patients were named! However, they were little more than a litany of events, there were no explicit learning points and no attempt was made to generalise the findings.

"A report that is well observed and linked to the published literature can be valuable even if there is nothing unique in the detail of the case. Lessons learnt, documented and shared, even if they are old lessons, are beneficial" (Jenkins, 2008).

A case report is brief account of the presentation, diagnosis and treatment and outcome of a patient. The majority of case reports are on one of six topics (Volkland and Iles, 1997):

- an unexpected association between diseases or symptoms

- an unexpected event in the course of observing or treating a patient

- findings that shed new light on the possible pathogenesis of a diseases or an adverse event

- unique or rare features of a disease

- unique therapeutic approaches

- a positional or quantitative variation of the anatomical structures

"Case reports permit discovery of new diseases and unexpected effects (adverse or beneficial) as well as the study of mechanisms, and they play an important role in medical education. Case reports and 
series have a high sensitivity for detecting novelty and therefore remain one of the cornerstones of medical progress; they provide many new ideas in medicine" (Vandenbroucke JP, 2001).

We welcome submission of case reports to British Journal Hospital Medicine. For us to consider publishing them they must identify something unique, unusual, or have a clear educational value to the journals' broad readership. The case report should make it clear how it adds to the body of medical knowledge. A good case report should help the reader recognise and manage a similar problem should one ever present itself (Wildsmith , 2003). All authors must have made an individual contribution to writing the case report and not just have been involved in the patient's care. This is a recommendation of the International Committee of Medical Journal Editors (ICMJE, 2013). If we are going to publish personal information about a living person, then we will require that person (or their guardian, if a child) gives written consent for publication. The signed informed consent form should accompany the manuscript at the time of submission.

Carleton HA and Webb ML (2012) The case report in context. Yale J Biol Med 85:93-6 Greenhow TW (1840) Mr Greenhow's Fracture Apparatus. Prov Med Surg J (1840). 1840;1:8-9 International Committee of Medical Journal Editors (2013) Recommendations for the Conduct, Reporting, Editing and Publication of Scholarly Work in Medical Journals. http://www.icmje.org/ (accessed 19 November 2013)

Jenkins D (2008) What shall we do with case reports? http://blogs.bmi.com/casereports/2008/11/14/what-shall-we-do-with-case-reports/( (accessed 18 November 2013) No Author listed (1840) Operations by Sir John Fife. Prov Med Surg J; 1:9-10 Smith R (2009) hhttp://www.eurekalert.org/pub_releases/2009-03/fo1b-msh031909.php (accessed 18 November 2013)

Vandenbroucke JP (2001) In defense of case reports and case series. Ann Intern Med 134;330-4

Volkland D \& Iles RL (1997) Guidebook to better medical writing. Washington DC. Island Press. ISBN $0-961831$

Wildsmith J (2003) How to write a case report. In, Hall GM (editor) How to write a paper, $3^{\text {rd }}$ Edition, BMJ Books. ISBN 0-7279-1728-5 


\section{Robert Miller}

Editor-in-Chief

British Journal of Hospital Medicine

\section{Rebeca Linssen}

Editor

British Journal of Hospital Medicine

\section{KEY POINTS}

- Case reports are a way of communication something new or unusual learned from clinical practice

- Case reports have educational value

- For many medical students and junior doctors writing a case report is their first experience of publishing

- The patient must provide signed informed consent for publication 